\title{
Chrysobalanaceae do Parque Nacional da Serra da Canastra, Minas Gerais, Brasil
}

\author{
Chrysobalanaceae of Serra da Canastra National Park, Minas Gerais, Brazil
}

Paula Katiane Boesing Hemsing ${ }^{1,2}$ \& Rosana Romero ${ }^{1}$

\begin{abstract}
Resumo
O Parque Nacional da Serra da Canastra está localizado na porção sudoeste do estado de Minas Gerais, Região Sudeste do Brasil. Na área, Chrysobalanaceae está representada por Couepia grandiflora, Hirtella glandulosa, H. gracilipes, Licania humilis e Parinari obtusifolia. O tratamento da família para o Parque apresenta chave de identificação, descrições, ilustrações, dados de distribuição geográfica e comentários sobre as espécies. Palavras-chave: campo rupestre, cerrado, florística, unidades de conservação.
\end{abstract}

\begin{abstract}
Serra da Canastra National Park is located in southwestern Minas Gerais, Southeast Brazil. In the Park, Chrysobalanaceae is represented by Couepia grandiflora, Hirtella glandulosa, H. gracilipes, Licania humilis, and Parinari obtusifolia. A key to the species, descriptions, illustrations, distribution data, and comments about the taxa are provided.

Key words: campo rupestre, cerrado, floristics, conservation units.
\end{abstract}

\section{Introdução}

Chrysobalanaceae apresenta 531 espécies e 18 gêneros. Sete gêneros são neotropicais (Prance 2007), com um grande número de espécies arbóreas (Tabarelli \& Mantovani 1999). Seus representantes caracterizam-se pelas folhas simples e alternas, flores pentâmeras, com hipanto, pétalas livres (raramente ausentes), ovário súpero, estilete lateral ou na base do óvario e óvulos eretos (Barroso et al. 1984; Klein 1984; Prance 2007). É uma das famílias mais representativas na Amazônia em número de espécies (Daly \& Prance 1989), com seu principal centro de diversidade nas florestas de terras baixas (Gentry 1988). No Cerrado, a família está representada por 51 espécies, que ocupam diferentes fitofisionomias das formações campestres, savânicas e florestais do bioma (Sano et al. 2008).

O Parque Nacional da Serra da Canastra é considerado área prioritária para a conservação da flora de Minas Gerais, por apresentar importância biológica extrema (Drummond et al. 2005). Até o momento foram realizados nesta área tratamentos taxonômicos das famílias Annonaceae (Pontes \& Mello-Silva 2005), Apocynaceae (Farinaccio \&
Mello-Silva 2004; Morokawa 2009), Asteraceae (Nakajima \& Semir 2001), Bignoniaceae (Scudeller 2004), Malpighiaceae (Volpi 2006) e Melastomataceae (Romero \& Martins 2002; Silva \& Romero 2008), além de Leguminosae-Papilionoideae (Filardi et al. 2007). Dando continuidade aos estudos florísticos nesta importante Unidade de Conservação, o presente trabalho apresenta as espécies de Chrysobalanaceae, incluindo chave de identificação, descrições, comentários, dados de distribuição geográfica, bem como ilustrações das espécies.

\section{Material e Métodos}

O Parque Nacional da Serra da Canastra (PNSC; Fig. 1), localizado na região sudoeste do estado de Minas Gerais, foi criado em 3 de abril de 1972, por meio do Decreto Federal no 70.355 , com uma área de aproximadamente 200.000 ha. No Plano de Manejo desta Unidade de Conservação, o PNSC foi dividido em dois grandes blocos: (a) Chapadão da Canastra: constituída de uma área contínua e regularizada, com 71.525 ha, dentro dos limites dos municípios de São Roque de Minas, Delfinópolis e

\footnotetext{
'Universidade Federal de Uberlândia, Instituto de Biologia, C.P. 593, 38400-902, Uberlândia, MG, Brasil.

2 Autora para correspondência: paulahemsing@hotmail.com
} 
Sacramento; e (b) Chapadão da Babilônia: com aproximadamente 130.000 ha da área decretada, e ainda não regularizada, dentro dos limites dos municípios de Delfinópolis, São João Batista do Glória, Capitólio e Vargem Bonita. Grande parte dos estudos realizados no PNSC abrangeu a área regularizada, sendo no presente estudo considerada a área original do Parque. As coletas realizaram-se no Chapadão da Canastra e em algumas localidades do Chapadão da Babilônia, como nas serras de Delfinópolis, município de Delfinópolis, e serras de Furnas, municípios de Capitólio e São João Batista do Glória. A vegetação que recobre o Parque Nacional da Serra da Canastra é do tipo campestre, savânica e florestal. As fitofisionomias que mais se destacam são: campo rupestre, campo limpo, campo sujo, campo úmido, cerrado, cerrado rupestre, matas de galeria, mata ciliar e mata mesófila semidecídua (IBAMA 2005).

Os exemplares herborizados encontram-se depositados no Herbarium Uberlandense (HUFU), do Instituto de Biologia da Universidade Federal de Uberlândia, Minas Gerais e duplicatas foram doadas aos herbários K, MBM, RB e SPFR (siglas de acordo com Thiers 2009). As descrições morfológicas das estruturas vegetativas e reprodutivas das espécies foram realizadas com base no material coletado, adotando a terminologia de Radford (1986). As ilustrações foram feitas com base nos materiais coletados no PNSC. Dados de floração e frutificação foram obtidos das etiquetas contidas nas exsicatas. A descrição da família e os dados de distribuição geográfica foram baseados em Hooker (1867) e Prance (1972).

\section{Resultados e Discussão}

Foram identificadas cinco espécies de Chrysobalanaceae no Parque Nacional da Serra da Canastra: Couepia grandiflora (Mart.) Benth. ex Hook. f., Hirtella glandulosa Spreng., Hirtella gracilipes (Hook. f.) Prance, Licania humilis Cham. \& Schltdl. e Parinari obtusifolia Hook. f.

Couepia grandiflora, L. humilis e $P$. obtusifolia habitam preferencialmente formações abertas do Parque Nacional da Serra da Canastra ocorrendo em cerrado, campo sujo e campo rupestre. Já Hirtella glandulosa e $H$. gracilipes ocorrem em formações florestais, nas bordas de matas de galeria e de encosta.

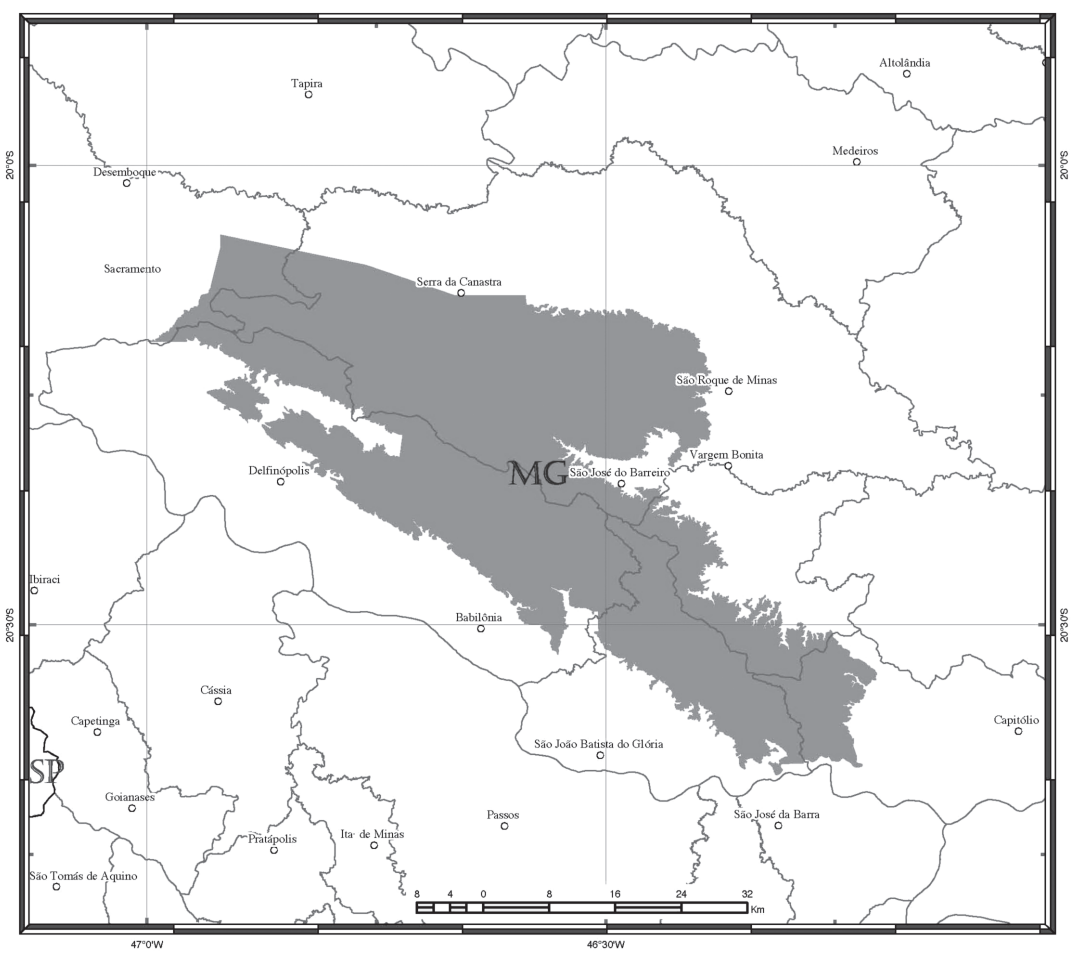

Figura 1 - Mapa do Parque Nacional da Serra da Canastra, Minas Gerais (adaptado de IBAMA 2005). Figure 1 - Map of Serra da Canastra National Park, Minas Gerais (after IBAMA 2005). 
Estudos florísticos no estado de Minas Gerais revelaram a ocorrência de três espécies de Chrysobalanaceae na Serra do Cipó (Giulietti et al. 1987), cinco na Serra do Cabral (Hatschbach et al. 2006) e seis em Grão Mogol (Assis 2003). Pelo menos metade dessas espécies ocorrem no PNSC. Prance (1988) citou 23 espécies para o estado de Goiás (incluindo o atual estado do Tocantins), cinco delas são comuns à Serra da Canastra, ao passo que, das 21 espécies do estado de São Paulo (Prance 2003), quatro são encontradas na área. Esses dados mostram que as espécies de Chrysobalanaceae do PNSC são típicas do Cerrado e se apresentam amplamente distribuídas neste bioma (Ratter et al. 2003).

As espécies de Chrysobalanaceae encontradas no Parque Nacional da Serra enquadram-se na categoria de não ameaçadas (LC) segundo os critérios propostos pela IUCN (2001).

\section{Tratamento Taxonômico}

Chrysobalanaceae R. Br. in Tuckey, Narr. exped. Zaire: 433. 1818.

Árvores ou (sub)arbustos. Folhas simples, alternas, margem inteira, peninérveas; estípulas caducas ou persistentes. Inflorescências em racemos, panículas ou menos frequentemente cimeiras, axilares ou terminais, bracteadas. Flores monoclinas, actinomorfas ou zigomorfas, pediceladas, às vezes sésseis; cálice pentâmero, imbricado, frequentemente glandular; disco nectarífero no hipanto; corola pentâmera ou apétala (em algumas espécies de Licania), dialipétalas, prefloração imbricada; estames 2 a muitos, livres, dispostos em um círculo completo ou unilaterais; anteras glabras, rimosas; estilete filiforme, basal ou lateral, incluso ou exserto; ovário súpero, geralmente unicarpelar, unilocular e biovulado, ou bilocular com um óvulo por lóculo; óvulos eretos. Frutos drupas, carnosos ou secos, sem endosperma; semente 1(2).

\section{Chave para identificação das espécies de Chrysobalanaceae do Parque Nacional da Serra da Canastra}

1. Panículas de espigas; flores sem corola..... 4. Licania humilis

1'. Panículas ou racemos; flores com corola.

2. Inflorescências com tricomas glandulares ou glândulas sésseis.

3. Panículas; bractéolas e lobos do cálice com tricomas glandulares estipitados

3'. Racemos; bractéolas e lobos do cálice com glândulas sésseis

2. H. glandulosa

'. Inflorescências sem tricomas glandulares ou glândulas sésseis.

4. Flores vistosas, 1,5-2 cm compr.; ca. 40 ou mais estames; filetes ultrapassando os lobos do cálice 1. Couepia grandiflora

4'. Flores inconspícuas, 4-7 mm compr.; 5-10 estames; filetes não ultrapassando os lobos do cálice 5. Parinari obtusifolia

1. Couepia grandiflora (Mart. \& Zucc.) Benth. ex Hook. f. in Martius \& Eichler, Fl. bras. 14(2): 46. 1867.

Fig. 2 a-c

Árvores ou arvoretas 1-5 m alt. Folhas discolores; pecíolo 5-8 mm compr., cilíndrico ou levemente canaliculado, moderadamente pubescente; lâmina 10,5-16×5-8 cm, oblonga, ápice arredondado, às vezes curto-acuminado, base arredondada, face adaxial glabra, face abaxial lanuginosa, acinzentada, 11-16 pares de nervuras proeminentes. Estípulas ca. 2 mm compr., subuladas, caducas. Panículas terminais, 10,5-23 cm compr., tomentosas, cinza-prateadas; brácteas e bractéolas 1,5-2 mm compr., ovais, persistentes, tomentosas. Flores vistosas, $1,5-2 \mathrm{~cm}$ compr., pedicelo 1,5-4 mm compr.; hipanto campanulado, externamente densamente pubescente; cálice com lobos ovais, agudos no ápice, tomentosos; pétalas brancas, ciliadas; estames ca. 40 ou mais, filetes livres, inseridos em um círculo completo, ultrapassando os lobos do cálice; ovário inserido no ápice do hipanto, densamente viloso, estilete piloso apenas no terço inferior. Fruto ca. $1,5 \times 2 \mathrm{~cm}$, oblongo. Material examinado: Capitólio: estrada para cachoeira Paraíso Perdido, 06.XI.2008, fr., L.S. Kinoshita 08-111 (HUFU). Delfinópolis: Paraíso Selvagem, trilha para mata do Canyon, 22.X.2003, fr., J.N. Nakajima et al. 3549 (HUFU). São Roque de Minas: estrada São Roque de Minas-Sacramento, 18.X.1994, fl., R. Romero et al. 1394 (HUFU, K, MBM, SPFR); $3 \mathrm{~km}$ da Guarita de Sacramento, 24.IX.1995, fl., R. Romero et al. 2732 (HUFU, K, MBM, SPFR); 18.XI.1995, fr., R. Romero 
et al. 3119 (HUFU); 19.VIII.1997, fl., R. Romero et al. 4407 (HUFU, MBM); 17.X.1997, fl., J.N. Nakajima et al. 2891 (HUFU, SPFR); estrada para Sacramento, 23.VIII.1997, fl., R. Romero et al. 4532 (HUFU); ca. 3 $\mathrm{km}$ da portaria de Sacramento, 1.X.1999, fl., R. MelloSilva et al. 1700 (HUFU); estrada principal, 26.IX.2002, fl., R. A. Pacheco et al. 206 (HUFU, K, SPFR).

Couepia grandiflora ocorre nos cerrados do Planalto Central do Brasil. No PNSC ocorre em cerrado, campo rupestre e campo sujo. Coletada com flores de outubro a dezembro e com frutos em outubro e novembro. Esta espécie se destaca por suas flores relativamente grandes, vistosas e com numerosos estames.

2. Hirtella glandulosa Spreng., Neue Entd. 1: 303. 1820. Fig. 2 d-g

Árvores, arvoretas ou arbustos 2-8 m alt. Folhas discolores; pecíolo 3-4 mm compr., cilíndrico, tomentoso quando jovem, hirsuto na maturidade; lâmina 8-12,5(-18) ×4-6,5(-8,2) cm, oblonga a oval, ápice acuminado a cuspidado, base arredondada a cuneada, às vezes subcordada, face adaxial glabra, exceto pelas glândulas sésseis na porção basal, face abaxial tomentosa, 8-13 pares de nervuras proeminentes. Estípulas 5-7 mm compr., lineares, caducas na maturidade. Panículas terminais, 16-25 cm compr., tomentoso-glandulosas; brácteas e bractéolas 2-5 mm compr., subuladas, persistentes, densamente tomentoso-glandulosas, tricomas glandulares estipitados. Flores 4-8 mm compr., pedicelo 1-2,5 cm, glabro; hipanto campanulado, externamente pubescente; cálice com lobos avermelhados a arroxeados, agudos no ápice, pubescentes, com numerosos tricomas glandulares estipitados; pétalas brancas, às vezes lilás apenas no ápice; 5 estames, livres, unilaterais, filetes brancos a arroxeados, ultrapassando os lobos do cálice; anteras lilás a vináceas; 4 estaminódios, opostos aos estames; ovário inserido no ápice do hipanto, pubescente, estilete roxo, hirsuto na base. Frutos 5-10 mm compr., globosos a elipsóides.

Material examinado: Delfinópolis: fazenda do José Onório, 29.XI.2003, fr., J.N. Nakajima et al. 3773 (HUFU); 29.XI.2003, fl. e fr., J.N. Nakajima et al. 3794 (HUFU, K, MBM, SPFR); Paraíso Selvagem, 11.X.2002, fl. e fr., R. Romero et al. 6432 (HUFU, K, MBM, SPFR); 22.X.2003, fl., J.N. Nakajima et al. 3563 (HUFU, K, MBM, SPFR); 14.IX.2004, fl. e fr., J.N. Nakajima et al. 3811 (HUFU, K, SPFR); 14.IX.2004, fl., R. Romero et al. 7064 (HUFU, K); 14.IX.2004, fl., C. A. Faria et al. 53 (HUFU, K, MBM, SPFR); 14.IX.2004, fl., E.K.O. Hattori et al. 370 (HUFU, K). São João Batista do Glória: Ribeirão Grande, pousada
Mata do Engenho, 6.XI.2008, fl. e fr., L.S. Kinoshita 08-119 (HUFU).

Hirtella glandulosa é comum no Planalto Central do Brasil, ocorrendo também nos cerrados da Amazônia e da Guiana. No PNSC ocorre em borda de mata de encosta e transição cerrado-mata de encosta. Foi coletada com flores e frutos de setembro a novembro. Difere das outras espécies do Parque pela presença de tricomas glandulares estipitados nas inflorescências, bractéolas e lobos do cálice e de glândulas sésseis na porção basal da face adaxial da lâmina foliar.

3. Hirtella gracilipes (Hook. f) Prance, Fl. Neotrop. 9:323. 1972.

Fig. $2 \mathrm{~h}-\mathrm{j}$

Árvores ou arbustos 3-6 m alt. Folhas concolores; pecíolo 1-4 mm compr., cilíndrico, pubescente; lâmina 5-10,5 ×1,8-4 cm, oblonga a oval, ápice acuminado, base obtusa a arredondada, raramente cuneada, ambas as faces esparsamente pubescentes a glabras, 6 ou 7 pares de nervuras proeminentes na face abaxial. Estípulas $0,8-1 \mathrm{~mm}$ compr., subuladas, caducas. Racemos terminais, 7$11,5 \mathrm{~cm}$ compr., laxos, esparsamente pubescentes; brácteas caducas na maturidade, bractéolas persistentes, ovais, 4-6 glândulas sésseis e translúcidas nas margens. Flor 3-9 mm compr., pedicelo 5-10 mm compr.; hipanto campanulado, externamente esparso-pubescente; cálice com lobos agudos no ápice, verdes a arroxeados, raramente vináceos, com glândulas sésseis e translúcidas; pétalas brancas a púrpuras; estames (5)6, livres, filetes brancos, ápice arroxeado, raramente vináceo, inseridos em semicírculo no hipanto, ultrapassando os lobos do cálice; ovário inserido na parede do hipanto, hirsuto, estilete hirsuto na base. Frutos não vistos.

Material examinado: Capitólio: 5.XI.2008, fl., L.S. Kinoshita 08-239 (HUFU); Cachoeira do Filó, 25.X.2006, fl., J.N. Nakajima et al. 4275 (HUFU, K, MBM); Cachoeira do Cânion, 26.X.2006, fl., J.N. Nakajima et al. 4402 (HUFU); estrada após Paraíso Perdido, 7.XI.2007, fl., R. Romero et al. 7954 (HUFU, K, MBM); 25.X.2006, fl., J.N. Nakajima et al. 4225 (HUFU, K, MBM); estrada para mineradora Gabi Extrações, 26.X.2006, fl., J.N. Nakajima et al. 4298 (HUFU, MBM); 8.XI.2007, fl., R. Romero et al. 8027 (HUFU, K, MBM); corrégo Quebra Anzol, 29.IX.2005, fl., J.N. Nakajima et al. 3886 (HUFU, K, MBM); 29.IX.2005, fl., J.N. Nakajima et al. 3916 (HUFU, K, SPFR). Delfinópolis: Cachoeirinhas, 22.XI.2000, fl., A.C.B. Silva 655 (HUFU, SPFR); Claro, 11.IX.1999, fl., S.A.P. Godoy et al. 1864 (HUFU, SPFR); fazenda do José Onório, 26.XI.2003, fl., R. Romero et al. 3741 (HUFU, K, MBM, SPFR); estrada para Gurita, 13.IX.2004, fl., C. A. Faria et al. 20 (HUFU, K); 29.IX.2002, fl., R. Romero et al. 6376 (HUFU, K, MBM, 


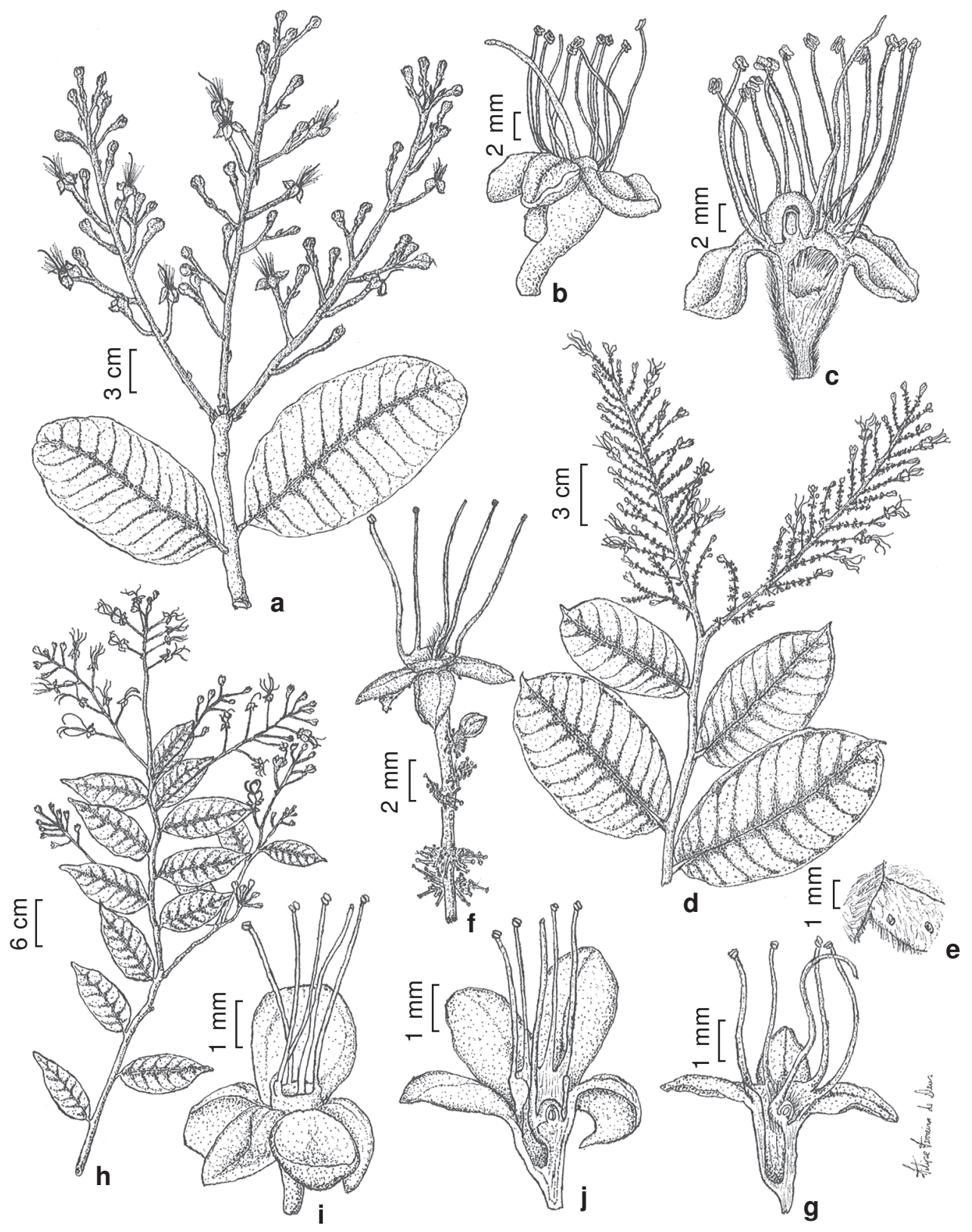

Figura 2 - a-c. Couepia grandiflora (Mart. \& Zucc.) Benth. ex Hook. f. (Pacheco 206) - a. ramo fértil; b. flor; c. secção longitudinal da flor. d-g. Hirtella glandulosa Spreng. (Romero 7064) - d. ramo fértil; e. detalhe da face abaxial da lâmina foliar mostrando glândulas sésseis; f. flor; g. secção longitudinal da flor. h-j. H. gracilipes (Hook. f.) Prance (Nakajima 3916) - h. ramo fértil; i. flor; j. secção longitudinal da flor.

Figure 2 - a-c. Couepia grandiflora (Mart. \& Zucc.) Benth. ex Hook. f. (Pacheco 206) - a. flowering branch; b. flower; c. longitudinal section of flower. d-g. Hirtella glandulosa Spreng. (Romero 7064) - d. flowering branch; e. detail of the abaxial surface of the leaf showing the sessile glands; f. flower, g. longitudinal section of flower. h-j. H. gracilipes (Hook. f.) Prance (Nakajima 3916) - h. flowering branch; i. flower; j. longitudinal section of flower. 
SPFR); fazenda Santa Bárbara, 10.IX.1999, fl., S.A.P. Godoy et al. 1816 (HUFU, SPFR); 10.X.1999, fl., A.C.B. Silva 40 (HUFU, SPFR); fazenda Águas da Serra, 13.III.2003, fl., $R$. Romero et al. 6764 (HUFU); Guarita, 14.IX.2000, fl., A.C.B. Silva 586 (HUFU, SPFR); Paraíso Selvagem, 04.XII.2002, fl., J.N. Nakajima et al. 3316 (HUFU); trilha para Cachoeira do Alpinista, 10.X.2002, fl., R.A. Pacheco et al. 213 (HUFU, K, MBM, SPFR); 15.IX.2004, fl., R. Romero et al. 7118 (HUFU); 15.IX.2004, fl., C.A. Faria et al. 69(HUFU, SPFR); 15.IX.2004, f1., E.K.O. Hattori et al. 431 (HUFU); 23.V.2007, fl., J.N. Nakajima et al. 4502 (HUFU, K, MBM). São Roque de Minas: cachoeira Casca D'Anta, 19.X.1994, fl. e fr., J.N. Nakajima et al. 612 (HUFU, K, MBM); 22.IX.1995, fl., $R$. Romero et al. 3219 (HUFU); estrada para a Cachoeira dos Rolinhos, 26.IX.1995, fl., R. Romero et al. 2843 (HUFU, K, MBM); trilha Paraíso Perdido, 8.XII.2005, fl., J.N. Nakajima et al. 4111 (HUFU, MBM, SPFR).

Hirtella gracilipes ocorre em matas ciliares e matas de encosta do Planalto Central brasileiro. No PNSC é frequente nesses ambientes. Foi coletada com flores entre maio e dezembro. Pode ser facilmente reconhecida pelas glândulas sésseis e translúcidas nas margens das bractéolas e lobos do cálice, além dos racemos terminais.

\section{Licania humilis Cham. \& Schltdl., Linnaea 2:} 549. 1827.

Fig. 3 a-c

Árvores 3-5m alt. Folhas concolores; pecíolo 5-6 mm compr., cilíndrico ou levemente canaliculado, densamente tomentoso; lâmina 4-9 ' 2,5-5 cm, oblonga a oval, ápice cuspidado, raramente arredondado, base arredondada, raramente obtusa, face adaxial glabra, face abaxial esparsamente lanuginosa, 8-10 pares de nervuras proeminentes na face abaxial. Estípulas ca. 3 $\mathrm{mm}$ compr., lineares, caducas. Inflorescências em panículas de espigas, 6,5-13,5 cm compr., tomentosas; brácteas e bractéolas 1,3-1,7 mm compr., ovais, pilosas; persistentes. Flores inconspícuas, 3-5 mm compr., sésseis, congestas, sem corola; hipanto campanulado, externamente pubescente; cálice com lobos agudos no ápice, pubescentes; estames 10, livres, filetes inseridos em um círculo completo, ultrapassando os lobos do cálice; ovário inserido na base do hipanto, densamente viloso, estilete piloso na porção inferior. Fruto ca. $2 \times 1 \mathrm{~cm}$, elipsóide.

Material examinado: Capitólio: Represa de Furnas, cachoeira Feixo da Serra, rio Turvo, 28.IX.2005, fl., $R$. Romero et al. 7174 (HUFU, K, MBM, SPFR). Delfinópolis: Trilha do Rio Claro, 30.VI.2000, fl.,A.C.B. Silva 507(HUFU, SPFR); estrada para Condomínio de Pedras, próximo à "casa azul", 17.V.2003, fl., R.A. Pacheco et al. 652 (HUFU, MBM); estrada para Casinha Branca, 25.X.2003, fr., J.N. Nakajima et al. 3698 (HUFU). São Roque de Minas: Cachoeira dos Rolinhos, 21.IX.1996, fl., J.N. Nakajima \& R. Romero 2060 (HUFU, K, MBM, SPFR).
Licania humilis ocorre nos cerrados do Planalto Central brasileiro. No PNSC ocorre exclusivamente em cerrado. Coletada com flores em setembro e outubro. É facilmente reconhecida por suas panículas de espigas congestas e flores sem pétalas.

5. Parinari obtusifolia Hooker f. in Martius \& Eichler, Fl. bras. 14(2): 52.1867.

Fig. 3 d-f

Subarbustos, arbustos ou arvoretas 0,4-2 $\mathrm{m}$ alt.

Folhas discolores; pecíolo 4-5 mm compr., canaliculado, tomentoso; lâmina 4,8-10×2,5-6 cm, oval a oblonga, raramente elíptica, ápice cuspidado, base arredondada, face adaxial glabra, raramente esparsamente pubescente, face abaxial pubescente, cinza-prateada, principalmente nas nervuras, 12-18 pares de nervuras proeminentes. Estípulas ca. $5 \mathrm{~mm}$ compr., elípticas a lanceoladas, caducas. Panículas terminais, 2-6,5 cm compr., ramificadas, pubescentes, sem brácteas nem bractéolas. Flores inconspícuas, 4-7 mm compr., subsésseis, pedicelo 2-3 mm compr.; hipanto subcampanulado, externamente velutino; cálice com lobos agudos no ápice, pubescentes; pétalas brancas a creme; 5-10 estames, livres, filetes não ultrapassando os lobos do cálice; ovário inserido na parede do hipanto, lanuginoso, estilete não ultrapassando os lobos do cálice, viloso na porção inferior. Frutos 1,4-1,7×1,7-2 $\mathrm{cm}$, oblongos, às vezes elipsóide.

Material examinado: São Roque de Minas: Chapadão da Canastra, km 45, 22.II.1994, fr., R. Romero et al. 693 (HUFU); estrada para Retiro de Pedras, 20.IV.1994, fl. e fr., R. Romero et al. 973 (HUFU); 16.XII.1998, fl., M. A. Farinaccio et al. 253 (HUFU); Guarita de Sacramento, 14.X.1994, fl. e fr. R. Romero et al. 1195 (HUFU, K, MBM, SPFR) e 1221 (HUFU, K, MBM); 24.IX.1995, fl., R. Romero et al. 2747 (HUFU); 19.VIII.1997, fr., R. Romero et al. 4422 (HUFU); posto de observação, 18.X.1994, fl. e fr., R. Romero et al. 1412 (HUFU); $2 \mathrm{~km}$ após Curral de Pedras, 19.X.1994, fl., R. Romero et al. 1319 (HUFU); 11.01.1995, fl., R. Romero et al. 1728 (HUFU); estrada para a Cachoeira dos Rolinhos, 26.IX.1995, fr., R. Romero et al. 2824 (HUFU); estrada para Sacramento, 27.IX.1995, fr., R. Romero et al. 2877(HUFU); estrada para a Fazenda do Fundão, 22.II.1997, fr., J.N. Nakajima et al. 2248 (HUFU); Vale dos Cândidos, próximo ao Córrego das Posses, 27.VI.1997, fl., R. Romero et al. 4308 (HUFU, K, MBM, SPFR); Chapadão do Diamante, 15.X.1997, fl., J.N. Nakajima et al. 2860 (HUFU); estrada principal, 26.IX.2002, fr., R.A. Pacheco et al. 186 (HUFU).

Parinari obtusifolia ocorre em cerrados e áreas abertas do Planalto Central brasileiro. No PNSC é frequentemente encontrada em campo sujo e, ocasionalmente, em áreas de cerrado, campo cerrado, campo rupestre e campo limpo. É reconhecida pelas panículas bastante ramificadas, curtas, $2-6 \mathrm{~cm}$ compr., e filetes não ultrapassando os lobos do cálice. 

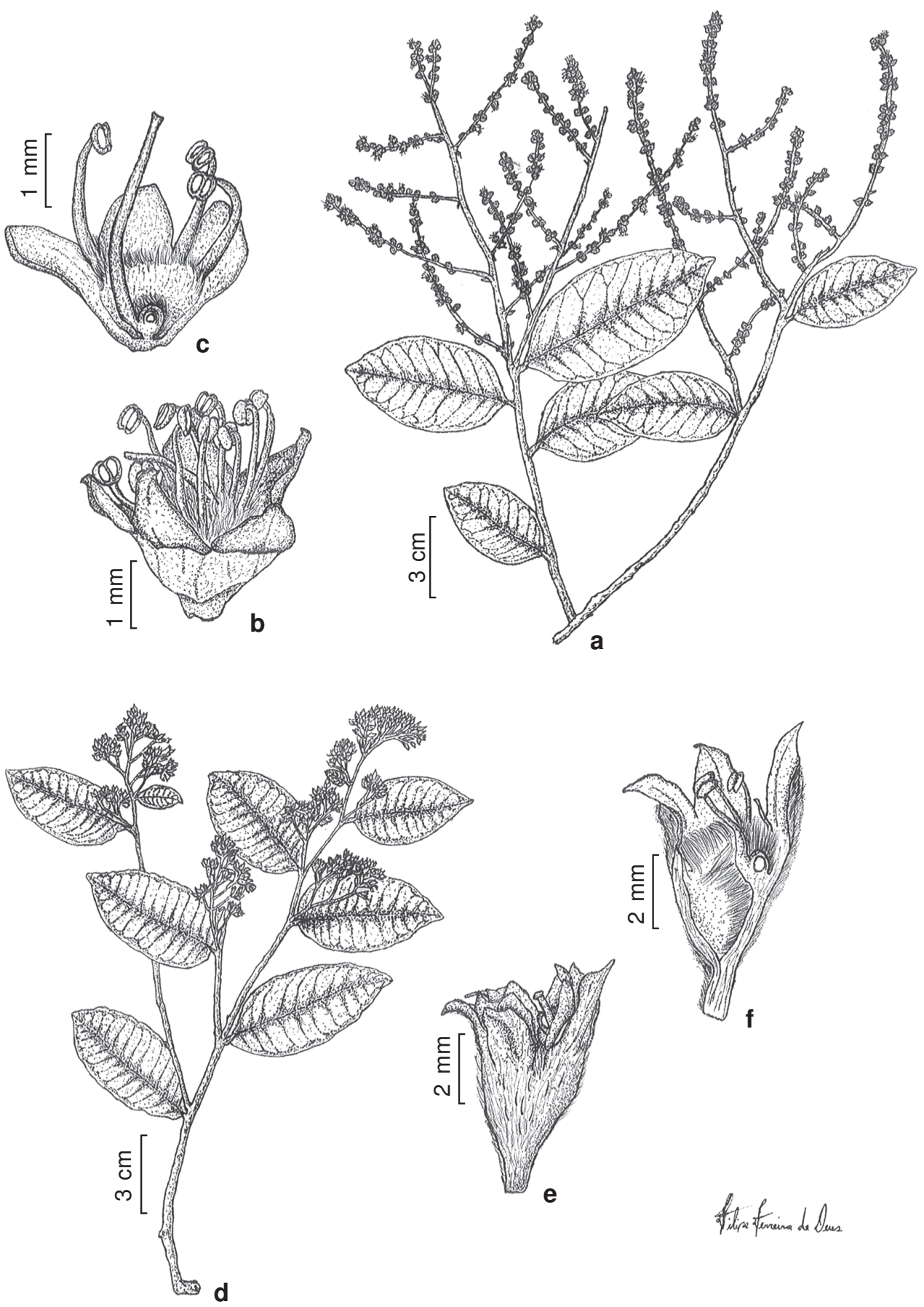

Figura 3 -a-c. Licania humilis Cham. \& Schltdl. (Pacheco 652) - a. ramo fértil; b. flor; c. secção longitudinal da flor. d-f. Parinari obtusifolia Hook. f. (Romero 1195) - d. ramo fértil; e. flor; f. secção longitudinal da flor.

Figure 3 - a-c. Licania humilis Cham. \& Schltdl. (Pacheco 652) - a. flowering branch; b. flower; c. longitudinal section of flower. d-f. Parinari obtusifolia Hook. f. (Romero 1195) - d. flowering branch; e. flower; f. longitudinal section of flower. 


\section{Agradecimentos}

Ao CNPq e à FAPEMIG o apoio financeiro para a realização das expedições de coleta ao Parque Nacional da Serra da Canastra, aos curadores dos herbários SPFR e UEC o envio de materiais, ao ilustrador Filipe de Deus a confecção das ilustrações e ao Dr. Jimi Naoki Nakajima a leitura e as sugestões.

\section{Referências}

Assis, M.C. 2003. Flora de Grão-Mogol, Minas Gerais: Chrysobalanaceae. Boletim de Botânica da Universidade de São Paulo 21: 169-172.

Barroso, G.M.; Peixoto, A.L.; Costa, C.G.; Ichaso, C.L.F.; Guimarães, E.F. \& Lima, H.C. 1984. Chrysobalanaceae. In: Sistemática de angiospermas do Brasil. Vol. 2. Universidade Federal de Viçosa, Viçosa. P. 15.

Daly, D.C. \& Prance, G.T. 1989. Brazilian Amazon. In: Campbell, D.G. \& Hammond, H.D. (eds.). Floristic inventory of tropical countries. New York Botanical Garden, New York. Pp. 401-426.

Farinaccio, M.A. \& Mello-Silva, R. 2004. Asclepiadoideae (Apocynaceae) do Parque Nacional da Serra da Canastra, Minas Gerais, Brasil. Boletim de Botânica da Universidade de São Paulo 22: 53-92.

Filardi, F.L.R.; Garcia, F.C.P.; Dutra, V.F. \& São-Thiago, P.S. 2007. Papilionoideae (Leguminosae) do Parque Nacional da Serra da Canastra, Minas Gerais, Brasil. Hoehnea 34: 383-408.

Gentry, A.H. 1988. Changes in plant community diversity and floristic composition environmental and geographical gradients. Annals of the Missouri Botanical Garden 75: 1-34

Giulietti, A.M.; Menezes, N.L.; Pirani, J.R.; Meguro, M. \& Wanderley, M.G.L. 1987. Flora da Serra do Cipó: Caracterização e lista das espécies. Boletim de Botânica da Universidade de São Paulo 9: 1-151.

Hatschbach, G.; Guarçoni, E.A.E; Sartori, M.A. \& Ribas, O.S. 2006. Aspectos fisionômicos da vegetação da Serra do Cabral, Minas Gerais, Brasil. Boletim do Museu Municipal de Curitiba 67: 1-33.

Hooker, J.D. 1867. Rosaceae: Chrysobalaneae. In: Martius, C.F.P. \& Eichler, A.G. (ed.). Flora brasiliensis. Typografia Regia, Monach. Vol. 14, pars 2. Pp. 5-56.

IBAMA - Instituto Brasileiro do Meio Ambiente. 2005. Plano de Manejo do Parque Nacional da Serra da Canastra. IBDF, Brasília. 799p.

Klein, R.M. 1984. Crisobalanáceas. In: Reitz, R. (ed.). Flora ilustrada catarinense. Herbário Barbosa Rodrigues, Itajaí. 24p.

Morokawa, R. 2009. Apocynaceae s. str. do Parque Nacional da Serra da Canastra (MG) e anatomia floral de Condylocarpon isthmicum (Vell.) A.DC. (Rauvofioideae). Dissertação de Mestrado. Universidade Estadual de Campinas, Campinas. 153p.

Nakajima, J.N. \& Semir, J. 2001. Asteraceae do Parque Nacional da Serra da Canastra, Minas Gerais, Brasil. Revista Brasileira de Botânica 24: 471-478.

Pontes, A. \& Mello-Silva, R. 2005. Annonaceae do Parque Nacional da Serra da Canastra, Minas Gerais, Brasil. Boletim de Botânica da Universidade de São Paulo 23: 71-84.

Prance, G.T. 1972. Chrysobalanaceae. Flora Neotropica 9: 1-409.

Prance, G.T. 1988. Chrysobalanaceae. In: Rizzo, J.A. (coord.). Flora do estado de Goiás. Vol. 10. Editora Universidade Federal de Goiás, Goiânia. 62p.

Prance, G.T. 2003. Chrysobalanaceae. In: Wanderley, M.G.L.; Shepherd, G.J.; Giulietti, A.M. \& Melhem, T.S. (eds.). Flora fanerogâmica do estado de São Paulo. Instituto de Botânica, São Paulo. Vol. 3. Pp. 33-44.

Prance, G.T. 2007. Chysobalanaceae. Rodriguésia 58: 493-531.

Radford, A. 1986. Fundamentals of plant systematics. Harper \& Row, New York. 498p.

Ratter, J.; Bridgewater, S. \& Ribeiro, J.F. 2003. Analysis of the floristic composition of the Brazilian cerrado vegetation III: Comparison of the woody vegetation of 376 areas. Edinburgh Journal of Botany 60: 57-109.

Romero, R. \& Martins, A.B. 2002. Melastomataceae do Parque Nacional da Serra da Canastra, Minas Gerais, Brasil. Revista Brasileira de Botânica 25: 19-24.

Sano, S.M.; Almeida, S.P. \& Ribeiro, J.F. 2008. Chrysobalanaceae. In: Cerrado: Ecologia e flora. Vol. 2. Embrapa Informação Tecnológica, Brasília. Pp. 649-652.

Scudeller, V. 2004. Bignoniaceae Juss. no Parque Nacional da Serra da Canastra - Minas Gerais, Brasil. Iheringia, serie Botânica 59: 59-73.

Silva, M.A.O. \& Romero, R. 2008. Melastomataceae das serras do município de Delfinópolis, Minas Gerais, Brasil. Rodriguésia 59: 609-647.

Tabarelli, M. \& Mantovani, W. 1999. A riqueza da floresta atlântica de encosta no estado de São Paulo (Brasil). Revista Brasileira de Botânica 22: 217-223.

Thiers, B. 2009. Index Herbariorum: A global directory of public herbaria and associated staff. New York Botanical Garden's Virtual Herbarium. Disponível em <http://sweetgum.nybg.org/ih>. Acesso em outubro 2009.

Volpi, R.L. 2006. Malpighiaceae no Parque Nacional da Serra da Canastra, Minas Gerais, Brasil. Dissertação de Mestrado. Universidade Federal do Paraná, Curitiba. 118p. 